\title{
Transmission of Activated-Episomal Banana streak OL (badna)virus (BSOLV) to cv. Williams Banana (Musa sp.) by Three Mealybug Species
}

\author{
J. B. Meyer, Du Roi Laboratory, Letsitele, 0885, South Africa; G. G. F. Kasdorf, ARC-Plant Protection Research \\ Institute, Queenswood, 0121, South Africa; L. H. Nel, Department of Microbiology and Plant Pathology, University \\ of Pretoria, 0002, South Africa; and G. Pietersen, Citrus Research International, c/o Department of Microbiology \\ and Plant Pathology, University of Pretoria, 0002, South Africa
}

\begin{abstract}
Meyer, J. B., Kasdorf, G. G. F., Nel, L. H., and Pietersen, G. 2008. Transmission of activatedepisomal Banana streak OL (badna)virus (BSOLV) to cv. Williams banana (Musa sp.) by three mealybug species. Plant Dis. 92:1158-1163.

Four different mealybug species (Dysmicoccus brevipes, Planococcus citri, P. ficus, and Pseudococcus longispinus) were evaluated for their ability to transmit putative activated-episomal Banana streak OL (badna)virus (BSOLV) to banana cv. Williams (Cavendish subgroup, AAA). Expressible endogenous sequences of banana streak viruses (BSVs) have been reported to be present in the DNA of various Musa hybrids, including FHIA-21 (AAAB). To obtain activated episomal BSOLV for this experimental transmission study, intentional stress by tissue culture propagation was applied to indexed FHIA-21 which, while free of other viruses, can contain activated episomal BSOLV. Immunocapture polymerase chain reaction and triple-antibody sandwich enzyme-linked immunosorbent assay results revealed that $13.4 \%$ of the derived progeny of the mother plants were infected with episomal BSOLV. Four of these BSOLV-infected progeny were used as sources of episomal virus for transmission studies. D. brevipes, Planococcus citri, and P. ficus mealybugs were able to transmit the putative activated episomal BSOLV. Control plants for the transmission experiments included FHIA-21 corms with no background history of tissue culture, as well as virus-free Williams plants. Episomal Banana streak GF (badna)virus (BSGFV) was transmitted from asymptomatic corm-derived FHIA-21 plants by $P$. citri and $P$. ficus. This is the first report of $P$. ficus as a vector of BSVs.
\end{abstract}

Additional keywords: acquisition access period, inoculation access period, ISEM, Musaceae, plantain, tetraploid

Banana and plantain (Musa spp. and hybrids) may be infected by a range of viruses, including Cucumber mosaic virus (CMV), various banana streak viruses (BSVs), and Banana bunchy top virus (BBTV). Plants resulting from micropropagated virus-free Musa meristems usually would be expected to remain free of viruses, and this is true for virus-free Cavendish (AAA) cultivars. However, with other genotypes of Musa, especially B genome hybrids, micropropagated plants sometimes have systemic (episomal) BSV infections, even if the original mother plant was indexed as BSV free (2). Recently, endogenous BSVs (suborder Pararetrovirinae) have been confirmed in Musa hybrids $(5,7,10,16,20,21)$. Some of these integrated sequences were shown to be expressible and cause banana streak dis-

Corresponding author: G. Pietersen

E-mail: gerhard.pietersen@up.ac.za

Accepted for publication 14 December 2007.

doi:10.1094/PDIS-92-8-1158

This article is in the public domain and not copyrightable. It may be freely reprinted with customary crediting of the source. The American Phytopathological Society, 2008. ease (BSD) as a result of the formation of episomal BSVs (16). Examination of various Musa genotypes revealed that integrated expressible sequences were associated mainly with Musa spp. having B chromosomes (6), and tissue culture propagation was demonstrated to be one of the stress factors to trigger episomal expression of integrated BSV sequences $(2,20)$.

Mealybugs (Hemiptera: Coccoidea: Pseudococcidae) have been reported as vectors of various plant viruses, including species of the Ampelovirus, Trichovirus, and Badnavirus genera (11). Nineteen species of mealybug belonging to 13 genera are known to occur on Musaceae (24) and transmission of BSVs from banana to banana, using Planococcus citri (Risso), has been demonstrated (15). Sugarcane bacilliform virus (SCBV) is serologically related to BSVs (14) and was transmitted from sugarcane to banana by Saccharicoccus sacchari (Cockerell) (15). Experimental transmission of BSVs also has been demonstrated with the pink pineapple mealybug Dysmicoccus brevipes (Cockerell) (12) and Pseudococcus comstiki (Kuwana) (22).

Because of the implication for international movement of tissue-culture-derived B-genome-containing material, the work described here aims to determine whether episomal Banana streak OL (badna)virus (BSOLV), putatively derived from integrated BSOLV sequences, could be transmitted to a Cavendish cultivar by four mealybug species.

\section{MATERIALS AND METHODS}

Establishment and indexing of source plants. Plants or corms were individually planted in 5-liter planting bags filled with fertilized potting soil. Plants were kept at 24 to $28^{\circ} \mathrm{C}$ in insectfree conditions with $12 \mathrm{~h}$ of artificial light daily. Samples from these plants were prepared for the BSV detection techniques by either (i) maceration with a mortar and pestle in BSV extraction buffer (phosphate-buffered saline [PBS: $137 \mathrm{mM} \mathrm{NaCl}, 8 \mathrm{mM} \mathrm{Na} \mathrm{HPO}_{4} \cdot 2 \mathrm{H}_{2} \mathrm{O}, 1.4$ $\mathrm{mM} \mathrm{KH} \mathrm{PO}_{4}, 2.7 \mathrm{mM} \mathrm{KCL}, 3 \mathrm{mM} \mathrm{NaN}$, $\mathrm{pH}$ 7.4] with $2 \%$ polyvinylpyrrolidone [PVP; MW 40,000] and $1 \% \mathrm{Na}_{2} \mathrm{SO}_{3}$ ), or (ii) by performing a partial virus purification as described by Diekmann and Putter (3).

Tissue-culture-derived FHIA-21. It has been shown that integrated BSOLV can be activated to an episomal form in cv. FHIA21 after micropropagation (2). Proliferating tissue of FHIA-21 (\#68, ITC.1332) on culture medium was imported under license from the International Network for the Improvement of Banana and Plantain (INIBAP) (South African permit no. P0010152). This material had been tested at INIBAP Virus Indexing Centres and, while free of other viruses, is known to sometimes contain episomal BSOLV activated from integrated sequences by tissue culture (2). Proliferating tissue subsequently was multiplied on modified culture medium of Murashige and Skoog (19), followed by three additional 4- to 6-week proliferating cycles. The medium was adjusted to $\mathrm{pH} 5.8$ prior to autoclaving. Shoot tips were transferred to rooting medium and maintained at $28^{\circ} \mathrm{C}$ with a $12-\mathrm{h}$ photoperiod of 1,000 lux daily. Potted plants, derived from proliferating tissue of FHIA-21, were assigned numbers ranging from TC-1 to TC-67. Plants were tested for BSOLV 4 months after planting.

FHIA-21 corms. Corms selected at FHIA, Honduras and originating from mother plants of FHIA-21 (AAAB) with no history of tissue culture were kindly 
provided by Dr. Dale Krigsvold and imported under license (South African import permit no. P0009722). The corms, numbered from $\mathrm{FH}-1$ to $\mathrm{FH}-8$, were expected to be free of episomal-activated BSOLV and were tested for infection by BSVs 9 months after planting.

$C v$. Williams recipient and control plants. In all, 200 virus-free tissue-culturederived plants of cv. Williams (Cavendish subgroup, AAA) were established. Four of these plants were set aside to serve as healthy source plants. Plants to be used as recipient and healthy control plants were tested prior to use and had no detected integrated sequences of BSVs, and no episomal virus was detected by triple-antibody sandwich enzyme-linked immunosorbent assays (TAS-ELISA; 7). Furthermore, no amplicons indicative of episomal virus were obtained with immunocapture polymerase chain reaction (IC-PCR) using the primer sets for BSOLV, BSV-RD, and Banana streak GF (badna)virus (BSGFV).

Virus status of experimental plants. The presence or absence of BSVs in all plant material was determined prior to conducting any transmission studies using published protocols for IC-PCR and TASELISA, and also occasionally confirmed with immunospecific electron microcopy (ISEM) $(3,8,23)$. Polyclonal antiserum to BSVs used in these tests was developed at the Agricultural Research Council, Plant Protection Research Institute (ARC-PPRI) against a wide range of BSVs (17). ICPCR was performed using primer sets BSV5317 (5'-AGTCATTGGGTCAAC CTCTGTCC-3') and BSV4673 (5'GGAATGAAAGAGCAGGCC-3'), BSVGF F1 (5'-ACGAACTATCACGACTTG TTCAAGC-3') and BSV-GF R1 (5'TCGGTGGAATAGTCCTGAGTCTTC-3'), and BSV-RD F1 (3'-ATCTGAAGGTGT GTTGATCAATGC-5') and BSV RD R1 (3'-GCTCACTCCGCATCTTATCAGTC$\left.5^{\prime}\right)$ in protocols for the detection of BSOLV, BSV-RD, and BSGFV as previously described $(4,8,9)$. BSV-RD is an isolate of BSOLV differing by only a few nucleotides and which originally was obtained from the Musa land race Red Dacca (5). The BSV5317/BSV4673 and BSV-RD $\mathrm{R} 1 / \mathrm{F} 1$ primer sets used in this study do not differentiate between BSOLV or BSV-RD and can amplify both isolates. BSGFV was obtained originally from the banana cv. Goldfinger in Australia (5). For IC-PCR, $25 \mu \mathrm{l}$ of goat anti-BSV serum, diluted 1:8000 in coating buffer $\left(15 \mathrm{mM} \mathrm{Na}_{2} \mathrm{CO}_{3}\right.$, $28 \mathrm{mM} \mathrm{NaHCO}_{3}$, and $0.02 \% \mathrm{NaN}_{3}, \mathrm{pH}$ 9.6) was placed in $0.5-\mu$ PCR tubes and incubated at $4^{\circ} \mathrm{C}$ for $16 \mathrm{~h}$. After washing the coated tubes two times with PBS with $0.05 \%$ Tween-20, pH 7.4 (PBST), samples were added and incubated for $4 \mathrm{~h}$ at $30^{\circ} \mathrm{C}$. After another three washes, a pre-prepared PCR master mix was added and PCR was performed in a Hybaid PCR Express thermocycler (Thermo Electron, Waltham,
MA). To detect integrated BSOLV in the FH-4 corm, PCR lacking the IC step also was performed with the above primers for BSOLV and BSV-RD using plant sap of FH-4 as template. In the TAS-ELISA goat anti-BSV serum (ARC-PPRI, diluted 1:8000), rabbit anti-BSV serum (ARCPPRI, diluted 1:8000) and goat-anti-rabbit alkaline phosphatase conjugated antibody (GAR-AP; ARC-PPRI) were used for detection of the virus. Incubation times were either for $16 \mathrm{~h}$ at $4^{\circ} \mathrm{C}$ or $4 \mathrm{~h}$ at $30^{\circ} \mathrm{C}$. Between each step, plates were washed three to five times at 3-min intervals with PBST using a TECAN ELISA multiwasher (Amersham, Piscataway, $\mathrm{NJ}$ ). Absorbance values were measured 1 $\mathrm{h}$ after substrate addition using a Labsystem multiscan MS reader (Amersham) at an optical density of $405 \mathrm{~nm}\left(A_{405 \mathrm{~nm}}\right)$. Average absorbance values were utilized as a relative measure of virus titers and a positive-negative threshold of twice the average of the healthy controls was selected.

Confirmation of endogenous BSOLV in FHIA-21. Total DNA was extracted from FHIA-21 tissue-culture-derived plant TC-1 and from FHIA-21 corm-derived plant $\mathrm{FH}-4$ by the method of Gawel and Jarret (4). PCR was performed using primers Musa T3-2 and BSV510.2 according to published methods (13). Amplicons were cloned using the pGEM-T easy cloning kit (Promega Corp., Madison, WI) and transformed into JM109 high-efficiency competent cells according to the manufacturer's instructions. Clones were sequenced using an automated sequencer (University of Cape Town, Cape Town, South Africa) in forward and reverse directions using plasmid puc/M13 universal primers. Sequence data was processed and analyzed using DNAMAN (Lynnon Biosoft, Canada) and BLAST software (1).

Rearing of mealybugs. The four mealybug species, D. brevipes, $P$. citri, P. ficus, and Pseudococcus longispinus, were evaluated separately in the transmission studies. All colonies except $P$. longispinus were raised on detached butternut fruit ( $\mathrm{Cucur}$ bita moschata) in separate Perspex cages of 0.4 by 0.4 by $0.6 \mathrm{~m}$ (length by width by height) with mesh-covered ventilation holes. Cages were placed on trays filled with oil. D. brevipes was obtained on pineapple stalks from the ARC-Pineapple Research Station in Hluhluwe, Kwazulu Natal, South Africa (kindly provided by H. A. Tustin). Planococcus citri was received from a laboratory colony kept at Citrus Research International in Nelspruit, Mpumalanga, South Africa (kindly provided by B. Tate). P. ficus females with egg sacks were received from Dr. V. Walton, (University of Stellenbosch). Pseudococcus longispinus was received from the University of Pretoria (UP), South Africa (kindly provided by Dr. K. Krüger). P. longispinus was kept on a Philodendron sp. at UP and pieces of leaf and petioles were brought directly to ARC-PPRI for placement on individual source and control-source plants for the required acquisition access period. The identities of the mealybugs were confirmed by Dr. Ian Millar, ARCPPRI, by morphological examination and use of existing taxonomic keys by (18). Voucher specimens were mounted and maintained at the South African National Collection of Insects under the following accession numbers: D. brevipes (HC6930), Planococcus ficus (HC6839), P. citri (AC164), and Pseudococcus longispinus (2007/193)

Transmission experiments. Each transmission experiment consisted of three treatments: (i) transmission from a tissueculture-derived FHIA-21 plant (positive for activated episomal BSOLV) to 10 Williams recipient plants; (ii) transmission from FHIA-21 (FH-4) corm-derived plants, negative for episomal BSOLV but infected with episomal BSGFV, to 10 Williams recipient plants; and (iii) transmission from virus-free Williams to 10 Williams recipient plants as the negative control treatment. The tissue-culture-derived FHIA-21 that served as donor plants were those with the highest, most similar average absorbance values as determined by BSV ELISA and included TC-10 $\left(A_{405 \mathrm{~nm}}=\right.$ 0.948; Planococcus citri $)$, TC- $12,\left(A_{405 \mathrm{~nm}}\right.$ $=0.856 ;$ P. ficus $)$, TC $-5\left(A_{405 \mathrm{~nm}}=0.909 ; D\right.$. brevipes $)$, and TC-26 $\left(A_{405 \mathrm{~nm}}=0.957\right.$; Pseudococcus longispinus). The healthy control had an average $A_{405 \mathrm{~nm}}=0.040$.

Acquisition access period. Potted donor plants were placed separately into insect-proof cages. Transmissions with each mealybug species were done separately in an insect-proof facility. Pieces of butternut squash infested with mixed developmental stages of $D$. brevipes, Planococcus citri, or P. ficus were placed on the donor leaves. In the transmission study where Pseudococcus longispinus was used, Philodendron leaf petioles with sufficient numbers of mealybugs were used and individuals were allowed to crawl off onto donor plant leaves; Philodendron petiole pieces were removed after 1 day. A 48-h acquisition access period was allowed for mealybugs that had migrated to the Musa donors. This has been reported to be the optimal time for virus acquisition, whereas a 120-h inoculation access period is regarded as the optimal time for virus transmission (12).

Inoculation access period. Following the 48-h acquisition access period, leaves infested with mealybugs were removed from each donor source plant and carefully cut into smaller pieces using sterile scissors. An estimation of the number of mealybugs on each donor leaf piece was made to ensure that equal numbers of mealybugs would be placed on each healthy recipient plant. To prevent movement of mealybugs between recipient plants, labeled cv. Wil- 
liams recipient plants were placed on individual round $(6-\mathrm{cm}$ radius) plastic blocks in such a way that plants did not touch each other, and plants of each treatment were housed in separate stainless steel trays $(1.35$ by $0.5 \mathrm{~m})$ filled with soapy water. Leaf pieces with mealybugs from each treatment were put onto cv. Williams recipient plants. D. brevipes individuals were slow to climb off of donor plant pieces placed on the recipient plants; therefore, a soft paintbrush was used to place individuals carefully at the leaf bases where the petiole folds around the stem. A 120-h feeding period was allowed, after which the number of mealybugs feeding on each recipient plant was counted, and mealybugs then were killed using both systemic and contact insecticides. Plants were kept in an insect-proof facility at 24 to $28^{\circ} \mathrm{C}$ under $12 \mathrm{~h}$ of artificial illumination per day.

Evaluation of BSVs transmission to recipient plants. At 3 and 6 months after inoculation, recipient plants were evaluated with TAS-ELISA and IC-PCR in order to evaluate the transmission of episomal BSVs.

\section{RESULTS}

BSV status of FHIA corms. FHIA-21 corms with no tissue culture background were imported from Honduras to serve as negative control donors containing only unexpressed BSVs. These were expected to be free of episomal BSVs because of the absence of tissue culture stresses on the plant. FH-3 and FH-7 were two corm-derived plants with positive average absorbance values in TAS-ELISA (Table 1) and also were positive by ISEM detection of bacilliform particles (Table 1). It is possible to distinguish between integrated and episomal BSVs by testing plants with both PCR and IC-PCR. PCR without the IC step would detect integrated or episomal BSVs because of the presence of contaminating plant DNA containing integrated BSV sequences. These contaminating integrated sequences would be removed when the IC step is followed by a washing step and only episomal BSVs would be detected (8). With IC-PCR, single or multiple episomal BSVs initially were detected in seven of the eight corms (all except FH8; Table 1). Therefore, FH-4 was selected as control plant because BSOLV was de-

Table 1. Detection of episomal banana streak viruses (BSVs) in FHIA-21 corms with no history of in vitro propagation using three different detection methods

\begin{tabular}{|c|c|c|c|c|c|}
\hline \multirow[b]{2}{*}{ Corm no. } & \multicolumn{3}{|c|}{ IC-PCR $^{\mathbf{a}}$} & \multirow{2}{*}{$\frac{\text { ELISA }^{b}}{A_{405 \mathrm{~nm}}}$} & \multirow{2}{*}{$\begin{array}{c}\text { ISEM }^{\mathrm{c}} \\
\text { Particles }\end{array}$} \\
\hline & BSOLV & BSGFV & BSV-RD & & \\
\hline FH-1 & - & - & + & 0.054 & None \\
\hline FH-2 & + & + & + & 0.052 & None \\
\hline FH-3 & + & + & + & 0.086 & Yes \\
\hline FH-4 & - & + & - & 0.058 & None \\
\hline FH-5 & + & + & + & 0.065 & None \\
\hline FH-6 & + & + & + & 0.063 & None \\
\hline FH-7 & + & + & + & 0.758 & Yes \\
\hline FH-8 & - & - & - & 0.058 & None \\
\hline Buffer & - & - & - & 0.023 & None \\
\hline Healthy ${ }^{\mathrm{d}}$ & - & - & - & 0.032 & None \\
\hline Positive $^{\mathrm{e}}$ & + & + & + & 1.092 & Yes \\
\hline
\end{tabular}

${ }^{a}$ Immunocapture polymerase chain reaction (IC-PCR) for Banana streak OL (badna)virus (BSOLV), Banana streak GF (badna)virus (BSGFV), and BSV-RD.

b Value in bold indicates positive enzyme-linked immunosorbent assay (ELISA) result. $A_{405 \mathrm{~nm}}=\mathrm{ab}-$ sorbance at an optical density of $405 \mathrm{~nm}$.

c ISEM = immunospecific electron microcopy.

${ }^{\mathrm{d}}$ Healthy controls are cv. Williams plants.

e Positive control is ARC-PPRI accession number 99/2722, known to be infected with episomal BSOLV and BSGFV.

tected in it by conventional BSOLV (data not shown) and BSV-RD PCR (Fig. 1, lanes 10-12), but not with IC-PCR using these two primer sets, suggesting the presence of integrated BSOLV only. Results in Table 1 illustrate the sensitivity of IC-PCR relative to ELISA and ISEM. Ideally, the corm-derived control plant should be free of episomal BSOLV. Although FH-8 initially complied with this criterion, episomal BSOLV was detected in this corm in subsequent tests (Fig. 2; other data not shown). The FH-4 corm remained negative for episomal BSOLV when tested on several occasions throughout this study. Unfortunately, however, this plant was infected with episomal BSGFV in spite of never showing any symptoms during the duration of the study. The presence of the BSGFV may be attributed to an external virus infection of FH-4 in Honduras rather than the result of activated-integrated BSGFV by unknown stress factors.

BSVs status of donor FHIA-21 tissueculture-derived plants. FHIA-21 plantlets known to contain integrated BSOLV were obtained from INIBAP following virus indexing by the INIBAP Virus Indexing Centers (INIBAP-VIC). These plantlets were subjected to serial tissue culture propagation to increase the likelihood of obtaining activated-episomal BSOLV (2). In all, $13 \%$ of the progeny were infected with episomal BSOLV after three to four subcultures, and these also developed symptoms of BSD. To confirm the presence of endogenous BSOLV, BSOLV DNA was amplified with primers Musa T3-2 and BSV510.2 (21) from the progeny plantlet TC-1, then cloned and sequenced. The cloned sequence shared $98.8 \%$ identity with GenBank accession AF106946 (endogenous BSOLV adjacent to a portion of Musa genome; data not shown). Episomal BSOLV was detected by BSOLV or BSV-RD IC-PCR tests in eight tissue culture plants (Fig. 2) which also tested positive in TAS-ELISA. The four plants with the most similar absorbance values were selected as donor plants. No BSGFV was detected by IC-PCR in any of the tissueculture-derived plants.

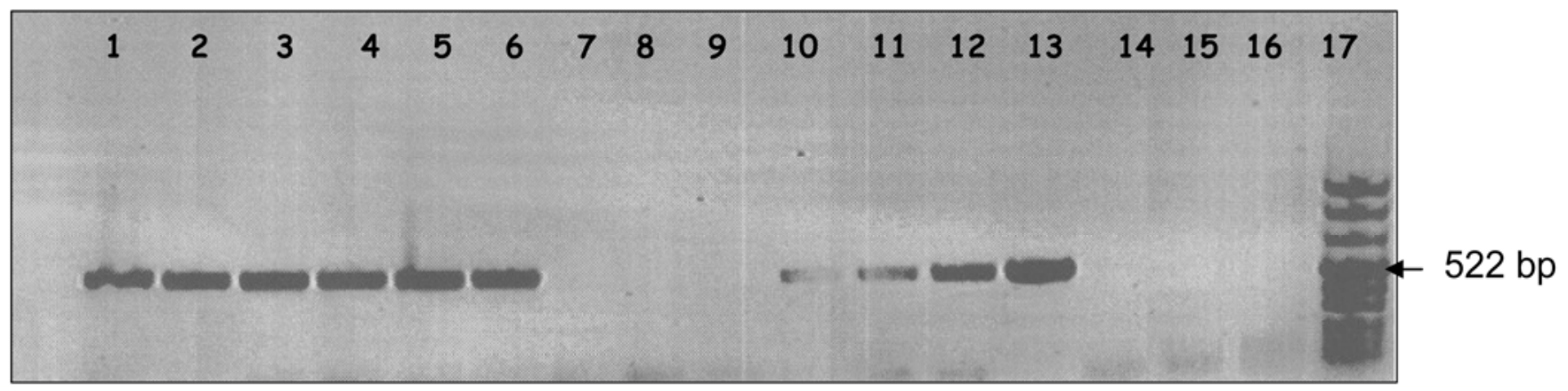

Fig. 1. Agarose gel analysis of amplicons of Banana streak OL (badna)virus-RD strain (BSV-RD) derived from polymerase chain reaction analysis of three total DNA extracts from plants used as donors from TC-5 (lanes 1-3), TC-1, (lanes 4-6), virus-free Williams (lanes 7-9), FH-4 corm (lanes 10-12), plasmid clone control (lane 13), healthy control (lanes 14 and15), buffer control (lane 16), and marker VIII (lane 17). 
Evaluation of the transmission of BSVs. None of the recipient plants on which mealybugs from the cv. Williams control plants had been allowed to feed were positive in IC-PCR and TAS-ELISA tests for BSVs at 3 or 6 months post inoculation (data not shown). To determine vector transmission of BSVs to Cavendishtype Musa spp., cv. Williams recipient plants of each treatment were tested individually with IC-PCR and ELISA at 3 and 6 months post transmission. Results after 6 months were essentially the same as at 3 months for all species (data not shown).

Transmission with Planococcus citri. The results 3 months after the transmission of episomal BSVs with $P$. citri are summarized in Table 2. Successful transmission of episomal BSOLV from tissue-culturederived plants to cv. Williams plants by $P$. citri was confirmed with TAS-ELISA and IC-PCR. No transmission of BSGFV was detected. Numbers of mealybug feeding on individual recipient plants during the inoculation access period ranged from 2 to 25. Absorbance values $\left(A_{405 \mathrm{~nm}}\right)$ were high (1.153 to 1.963$)$ in all $\mathrm{cv}$. Williams plants to which BSOLV was transmitted, whereas the average $A_{405 \mathrm{~nm}}$ of the healthy control was 0.141 . When the FH-4 corm was used as donor plant (contains integrated but not episomal BSOLV but also contains episomal BSGFV), no transmission of BSOLV was obtained; however, successful transmission of BSGFV to 5 of the 10 recipient Williams plants was demonstrated (Table 2). In all cases, TAS-ELISA results correlated with the IC-PCR results. Absorbance values $\left(A_{405 \mathrm{~nm}}\right)$ recorded for Williams plants infected with BSGFV ranged from 0.310 to 0.511 .

Transmission with $P$. ficus. $P$. ficus transmitted episomal BSOLV from TC-12 to 8 of the 10 recipient plants as detected by BSOLV PCR, whereas BSV-RD PCR indicated that 7 of 10 plants were infected (Table 2). This is the first report of this mealybug as a vector of BSVs. Between 7 and 60 mealybugs survived the inoculation access period on recipient plants that ultimately became infected. Absorbance values $\left(A_{405 \mathrm{~nm}}\right)$ from TAS-ELISA ranging from 0.509 to 1.059 ( 0.039 for healthy control) were recorded for recipient plants infected from TC-12, and IC-PCR corroborated the TAS-ELISA results. BSD symptoms were observed in the second month after vector transmission. BSGFV was transmitted from the FH-4 corm to 3 of the 10 recipient plants by $P$. ficus. In all, 18,11 , and 5 mealybugs were counted on each of these plants at the conclusion of the inoculation access period. TAS-ELISA of infected recipient plants yielded absorbance values $\left(A_{405 \mathrm{~nm}}\right)$ ranging from 0.134 to 0.189 .

Transmission with D. brevipes. Results of transmission of episomal BSVs by $D$. brevipes at 3 months post transmission are summarized in Table 2. Due to the reluctance of the mealybugs to move to Musa spp., low numbers survived the inoculation access period; however, despite this, TASELISA and IC-PCR showed that the virus was transmitted from TC-5 to 2 of the 10 Williams recipient plants (2 as detected by both BSOLV [1/10] and BSV-RD [2/10] PCR tests). These transmissions were obtained with four and seven mealybugs, respectively, surviving the inoculation access period. TAS-ELISA absorbance values $\left(A_{405 \mathrm{~nm}}\right)$ of 1.044 and $0.791(0.045$ for healthy control) were found with the BSV-infected plants. No episomal BSGFV

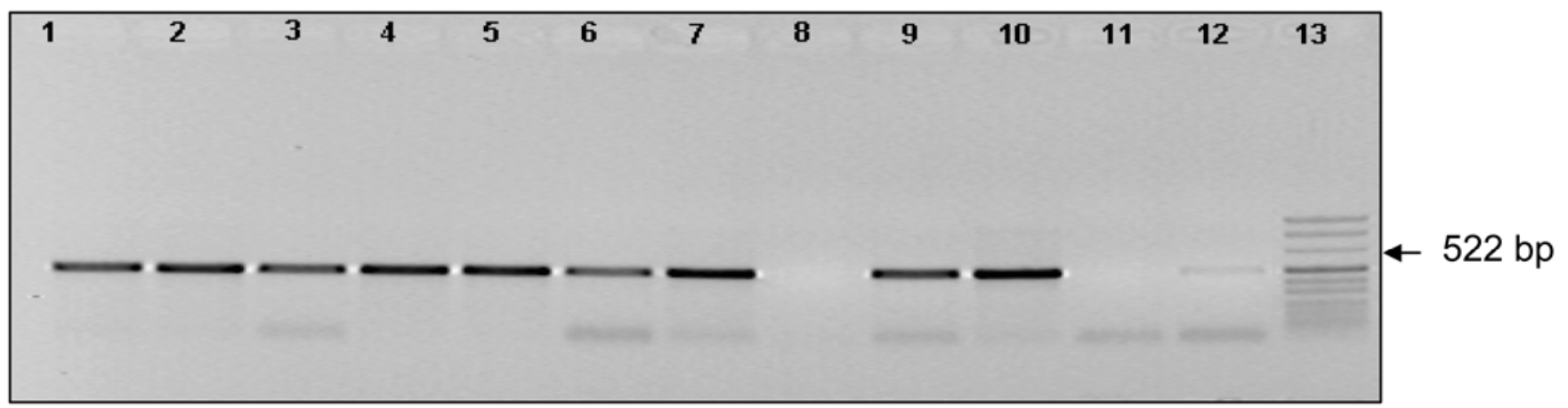

Fig. 2. Agarose gel analysis of immunocapture polymerase chain reaction-derived (primers banana streak virus [BSV] RD R1/F1) amplicons of Banana streak OL (badna)virus (BSV-OL) from tissue-culture-derived FHIA-21 plants. Lanes 1-13: TC-5, TC-10, TC-12, TC-15, TC-26, TC-39, TC-43, TC-66, TC67, plasmid positive control, virus-free Grand Nain, FH-8, and marker VIII, respectively.

Table 2. Immunocapture polymerase chain reaction (IC-PCR) detection of episomal banana streak viruses (BSVs) in receptor plants 3 months post mealybug transmission

\begin{tabular}{|c|c|c|c|c|c|}
\hline \multirow[b]{2}{*}{ Vector, donor ${ }^{\mathrm{c}}$} & \multicolumn{3}{|c|}{ No. of plants positive by IC-PCR ${ }^{a}$} & \multicolumn{2}{|c|}{ Range of live mealybugs ${ }^{b}$} \\
\hline & BSGFV & BSOLV & BSV-RD & Resulting in BSV infection & Not resulting in BSV infection \\
\hline \multicolumn{6}{|l|}{ Planococcus citri } \\
\hline TC-10 & $0 / 10$ & $10 / 10$ & $10 / 10$ & 2 to 25 & NA \\
\hline FH-4 & $5 / 10$ & $0 / 10$ & $0 / 10$ & 8 to 30 & 6 to 10 \\
\hline Williams & $0 / 10$ & $0 / 10$ & $0 / 10$ & NA & 10 to 30 \\
\hline \multicolumn{6}{|l|}{ P. ficus } \\
\hline TC-12 & $0 / 10$ & $8 / 10$ & $7 / 10$ & 7 to 60 & 3 to 4 \\
\hline FH-4 & $3 / 10$ & $0 / 10$ & $0 / 10$ & 5 to 18 & 6 to 26 \\
\hline Williams & $0 / 10$ & $0 / 10$ & $0 / 10$ & NA & 4 to 7 \\
\hline \multicolumn{6}{|c|}{ Dysmicoccus brevipes } \\
\hline TC-5 & $0 / 10$ & $1 / 10$ & $2 / 10$ & 4 to 7 & 2 to 8 \\
\hline FH4 & $0 / 10$ & $0 / 10$ & $0 / 10$ & NA & 2 to 7 \\
\hline Williams & $0 / 10$ & $0 / 10$ & $0 / 10$ & NA & 2 to 4 \\
\hline \multicolumn{6}{|c|}{ Pseudococcus longispinus } \\
\hline TC-26 & $0 / 10$ & $0 / 10$ & $0 / 10$ & NA & 1 to 12 \\
\hline $\mathrm{FH} 4$ & $0 / 10$ & $0 / 10$ & $0 / 10$ & NA & 5 to 30 \\
\hline Williams & $0 / 10$ & $0 / 10$ & $0 / 10$ & NA & 4 to 35 \\
\hline
\end{tabular}

a Banana streak GF (badna)virus (BSGFV), Banana streak OL (badna)virus (BSOLV), and BSV-RD.

${ }^{\mathrm{b}}$ Range of live mealybugs present post inoculation access period; NA = not applicable, no samples in this category.

c Plants derived from either tissue-culture-propagated FHIA-21 plants (TC), corms (FH4) with no history of tissue culture, or healthy donors of cv. Williams. 
was transmitted by $D$. brevipes from the FH-4 donor to the recipient plants.

Transmission with Pseudococcus longispinus. The results for the transmission of episomal BSV using $P$. longispinus are summarized in Table 2. Even thought the TC-26 donor had an absorbance value $\left(A_{405 \mathrm{~nm}}=0.956\right)$ suggesting that it was positive for episomal BSVs, both IC-PCR and TAS-ELISA (data not shown) indicated that no transmission to cv. Williams plants from this source occurred. Similarly, no transmission of BSGFV was obtained using the FH-4 corm as virus donor even with mealybug numbers as high as 30 per plant.

\section{DISCUSSION}

The aim of this study was to determine whether episomal BSOLV putatively derived from expressed integrated BSOLV sequences could be transmitted by various Musa-colonizing mealybug species to a Cavendish cultivar. Intentional stress caused by tissue culture propagation was used to activate expressible-integrated sequences of BSOLV in the Musa tetraploid FHIA-21 for use in transmission studies. This resulted in $13.4 \%$ of episomally infected progeny. This supports past studies. Dallot et al. (2) demonstrated that FHIA-21 plants which were negative for episomal BSVs prior to micropropagation yielded 15 to $58 \%$ of progeny infected with episomal BSVs after six in vitro subcultures, suggesting that a stress mechanism induced by tissue culture propagation is involved in the activation of integrated BSVs. This was confirmed in a later study in which Musa cultivars (including FHIA21) were shown to harbor expressible integrants when enzyme-digested products of the DNA from endogenous and episomal BSVs from the same cultivar were compared (16). The sequence of episomal BSVs from FHIA-21 was virtually identical to the integrated BSOLV sequences (16). In the current study, the presence of the endogenous form of BSOLV in FHIA21 was confirmed based on amplification and sequencing of a band of the expected size after PCR amplification with the primers MusaT3-2 and BSV510.2 (2,21). BSV510.2 targets a region in the BSOLV genome and was designed from BSOLV integrated sequences in a hybrid (Obino L'Ewai $\times$ Calcutta-4) host genome (21) whereas MusaT3-2 targets a sequence in Musa plants close to the integration site of BSOLV.

A number of in vitro-derived FHIA-21 plants utilized in this study were showed by IC-PCR to contain episomal BSOLV, most probably originated from the integrated BSOLV sequences in the FHIA-21 genome following the tissue-culture-induced stress. Episomal BSGFV was absent from all tissue-derived FHIA-21 plants. It is unknown whether the BSVGF sequences found in the FH-2 to FH-7 corms were activated by stress on the plant or from episomal vector transmission in Honduras. Of the corms, only FH-7 showed signs of $\mathrm{BSD}$, displaying irregular yellow streaks on the leaf lamina. PCR is a more sensitive detection technique than ISEM or ELISA and may explain why some corms tested positive for BSGFV with IC-PCR but negative for BSVs with the other two techniques used. Primers specific to BSGFV were designed from BSGFV originating from cv. Goldfinger (5). This cultivar is accepted as a commercial cultivar in Australia and does not often display symptoms of BSD, which suggests that the integrant may have a low activation rate. In South Africa, BSD has not been reported in plantations established with this cultivar, although episomal BSGFV is present (17). All cv. Williams plants to which BSOLV or BSGFV was transmitted developed symptoms of BSD within the first 3 months after transmission, as did the FHIA-21 tissue-culture-derived plants.

In this study, three of the four mealybugs species were shown to efficiently transmit the putative activated-episomal BSOLV. P. longispinus was the only mealybug species that did not transmit BSOLV. The different tissue-cultured donor plants were selected because of similar, high ELISA absorbance values; therefore, it is unlikely that viral concentration influenced transmission efficiency. $D$. brevipes transmitted BSOLV to only 2 of 10 recipient plants, corroborating previous results of 26 to $48 \%$ transmission of BSVs (12). The acquisition and inoculation access periods reported by Kubiriba et al. (12) were utilized in this study to demonstrate the first transmission of episomal BSVs with Planococcus ficus, a vector that does not readily occur on Musa spp. However, this species has been recorded on related species, Ensete ventricosum (family Musaceae) in Ethiopia $(24,25)$. P. ficus also occurs in African countries, including South Africa (24). P. ficus and P. citri are morphologically very similar $(18,24)$ and both were shown in this study to be efficient vectors in transmitting activatedepisomal BSOLV from tissue-culture-derived FHIA-21 plants to Cavendish. P. citri was able to transmit BSOLV to 10 of 10 of the recipient plants whereas transmission by $P$. ficus was to 8 of 10 . As few as two $P$. citri mealybugs surviving the inoculation access period on the plants were required to still transmit the activated episomal BSOLV to Williams.

BSOLV was detected by PCR in total DNA extracts from FHIA-21 corm FH-4 but not with IC-PCR, demonstrating the presence of the integrated but not the episomal form of BSOLV in this material. None of the four mealybug species were able to transmit integrated BSOLV from the FH-4 corm to Williams as expected. However, $P$. ficus and $P$. citri were able to transmit episomal BSGFV from the as- ymptomatic FH-4 corm, confirming the ability of these two species to transmit episomal BSV. This episomal BSGFV was below the detection level thresholds for TAS-ELISA and ISEM in donor plants, yet transmission to 3 of the 10 recipient plants for $P$. ficus and 5 of the 10 for P. citri was demonstrated. The BSGFV strain has been found in asymptomatic tetraploid Musa cultivars occurring in South Africa (17), and these may serve as potential reservoirs of BSGFV that can be vectored by mealybugs to sensitive commercial Cavendish cultivars.

The results of this study suggest that episomal BSOLV, putatively activated from integrated forms of BSOLV in a tissue-culture-derived tetraploid, FHIA-21, can be efficiently transmitted by mealybug vectors to Cavendish cultivars. This has significant implications for the worldwide distribution of in vitro Musa planting material containing the B genome. However, the transmissions were conducted under laboratory conditions and the situation may differ under natural field conditions. Conditions in South African production areas do not seem to favor BSD expression (17), and no evidence of spread of BSOLV from $\mathrm{B}$ genome plantations to commercial Cavendish cultivars could be observed (17). Although it is likely that environmental conditions, plantation practices, and plant age will play a negative role in mealybug transmissions under field conditions, caution needs to be taken when planting new cultivars with endogenous BSOLV sequences that have high BSOLV activation rates among existing plantations.

\section{ACKNOWLEDGMENTS}

We thank the NRF-THRIP, South Africa, and the Banana Growers Association of South Africa for funding of this work; and I. M. Millar (Entomology, ARC-PPRI, Vredehuis, Pretoria, South Africa) for the taxonomic identification of the mealybug species.

\section{LITERATURE CITED}

1. Altshul, S. F., Madden, T. L., Schaffer, A. A., Zhang, J., Zhang, Z., Miller, W., and Barret, A. J. 1997. Gapped BLAST and PSI-BLAST: A new generation of protein database search programs. Nucleic Acids Res. 25:3389-3402.

2. Dallot, S., Acuña, P., Rivera, C., Ramírez, P., Cote, F., Lockhart, B. E. L., and Caruana, M. L. 2001. Evidence that the proliferation stage of micropropagation procedure is determinant in the expression of Banana streak virus integrated into the genome of the FHIA 21 hybrid (Musa AAAB). Arch. Virol. 146 (11):21792190.

3. Diekmann, D. R., and Putter, C. A. J. 1996. FAO/IPGRI. Technical Guidelines for the Safe Movement of Germplasm. No. 15, 2nd ed. Food and Agriculture Organization of the United Nations/International Plant Genetic Resources Institute, Rome.

4. Gawel, N. J., and Jarret, R. L. 1991. A modified CTAB DNA extraction procedure for Musa and Ipomoea. Plant Mol. Biol. Rep. 9:262-266.

5. Geering, A. D. W., McMichael, L. A., Dietzgen, R. G., and Thomas, J. E. 2000. Genetic diversity among Banana streak virus isolates from Australia. Phytopathology 90:921-927. 
6. Geering, A. D. W., Olszewski, N. E., Dahal, G., Thomas, J. E., and Lockhart, B. E. L. 2001. Analysis of the distribution and structure of integrated Banana streak virus DNA in a range of Musa cultivars. Mol. Plant Pathol. 2:207-213.

7. Geering, A. D. W., Olszewski, N. E., Harper, G., Lockhart, B. E. L., Hull, R., and Thomas, J. E. 2005. Banana contains a diverse array of endogenous badnaviruses. J. Gen. Virol. 86:511-520.

8. Harper, G., Dahal, G., Thottappilly, G., and Hull, R. 1999. Detection of episomal Banana streak badnavirus by IC-PCR. J. Virol. Methods 79:1-8.

9. Harper, G., and Hull, R. 1998. Cloning and sequence analysis of Banana streak virus DNA. Virus Genes 17(3):271-278.

10. Harper, G., Osuji, J. O., Heslop-Harrison J. S., and Hull, R. 1999. Integration of Banana streak badnavirus into the Musa genome: Molecular and cytogenetic evidence. Virology 255:207-213.

11. Hull, R., Lockhart, B. E. L., Reddy, D. V. R., and Schoelz, J. E. 2000. Caulimoviridae. Pages 335-337 in: Virus Taxonomy. Seventh Report of the International Committee on Taxonomy of Viruses. M. H. V. van Regenmortel, C. M. Fauquet, D. H. L. Bishop, E. B. Carstens, M. K. Estes, S. M. Lemon, J. Maniloff, M. A. Mayo, D. J. McGeoch, C. R. Pringle, and R. B. Wickner, eds. Academic Press, San Diego, CA.

12. Kubiriba, J., Legg, J. P., Tushemereirwe, W., and Adipala, E. 2001. Vector transmission of Banana streak virus in the screenhouse in
Uganda. Ann. Appl. Biol. 139:(1)37-43.

13. Lockhart, B. E. L. 1995. Banana streak badnavirus infection in Musa: epidemiology, diagnosis and control. Food Fertil. Technol. Cent. Tech. Bull. 143.

14. Lockhart, B. E. L., and Autrey, J. C. 1988. Occurrence in sugarcane of a bacilliform virus related serologically to banana streak virus. Plant Dis. 72:230-233

15. Lockhart, B. E. L., and Olszewski, N. E. 1993. Serological and genomic variability in Banana streak virus: implications for virus detection in Musa germplasm. Pages 105-113 in: Proc. INIBAP Conf. Breed. Banana Plantains Pest Dis. Resistance. Montpellier, France.

16. Lockhart, B. E. L, Ndowora, T. C., Olszewski, N. E., and Dahal, G. 1998. Studies on integration of Banana streak badnavirus sequences in Musa: identification of episomally-expressible badnaviral integrants in Musa genotypes. Pages 42-47 in: Banana streak virus: A Unique Virus-Musa Interaction? Proc. Workshop PROMUSA Virology Working Group. E. A. Frison and S. L. Sharrock, eds. INIBAP, Montpellier, France.

17. Meyer, J. B. 2005. Banana streak badnavirus, incidence, transmission and the development of a serologically based detection method. M.Sc. thesis, Department of Microbiology and Plant Pathology, University of Pretoria, South Africa.

18. Millar, I. M. 2002. Mealybug genera (Hemiptera: Pseudococcidae) of South Africa: identification and review. Afr. Entomol. 10:185-233.

19. Murashige, T., and Skoog, F. 1962. A revised medium for rapid growth and bio-assays with tobacco tissue cultures. Physiol. Plant. 15:472497.

20. Ndowora, T., Dahal, G., LaFleur, D, Hull, R. Olszewski, N. E., and Lockhart, B. E. L. 1999 Evidence that badnavirus infection in Musa can originate from integrated pararetroviral sequences. Virology 255:214-220.

21. Ndowora, T. R. C. 1998. Development of an immunoenzymatic assay to detect serologically diverse isolates of Banana streak virus and characterization of viral sequences integrated into the genome of Musa sp. Ph.D. thesis, University of Minnesota, St. Paul.

22. Su, H. J. 1998. First occurrence of Banana streak badnavirus and studies on its vectorship in Taiwan. Pages 20-25 in: Banana streak virus: A Unique Virus-Musa Interaction? Proc. Workshop PROMUSA Virology Working Group. E. A. Frison and S. L. Sharrock, eds. INIBAP, Montpellier, France.

23. Van Regenmortel, M. H. V., and Burckard, J. 1980. Detection of a wide spectrum of tobacco mosaic virus strains by indirect enzyme-linked immunosorbent assays. Virology 106:327-334.

24. Watson, G. W., and Kubiriba, J. 2005. Identification of mealybugs (Hemiptera: Pseudococcidae) on banana and plantain in Africa. Afr. Entomol. 13(1):35-47.

25. Williams, D. J., and Martile-Ferrero, D. 2000 A new species of the mealybug genus Cataenococcus Ferris from Ethiopia on Ensete ventricosum, a plant infected by a virus [Hemiptera, Pseudococcidae, Musaceae]. Rev. Fr. Entomol. (1999) 21:145-149. 